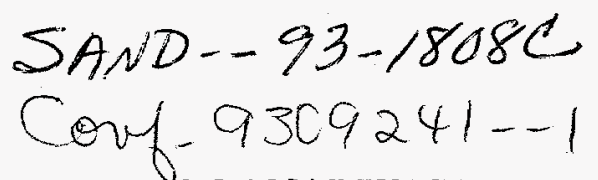

TITLE

\title{
DEVELOPMENTS IN CRYSTALLOGRAPHIC PHASE ANALYSIS IN THE SEM: BACKSCATTERED ELECTRON KIKUCHI PATTERNS
}

\author{
J. R. Michael, R. P. Goehner and C. R. Hills
}

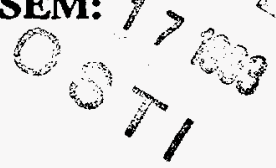

\section{Materials and Process Sciences Center, Sandia National Laboratories, Albuquerque, NM 87185}

Recent development of a charge coupled device (CCD) - based detector for the acquisition of backscattered electron Kikuchi patterns has enabled on-line crystallographic phase identification studies to be conducted in the scanning electron microscope. ${ }^{1}$ High quality patterns have been obtained from a wide variety of materials with relatively little specimen preparation compared to electron diffraction in the transmission electron microscope (TEM). Crystallographic phase identification through a combination of BEKP and energy dispersive $\mathrm{x}$-ray spectrometry is demonstrated by the identification of precipitates in a high temperature Ni-based alloy containing $\mathrm{Cr}$ and $\mathrm{W}$. The precipitates that formed in this alloy were identified as $\mathrm{M}_{6} \mathrm{C}$ or $\mathrm{M}_{23} \mathrm{C}_{6}$.

The CCD-based detector has been described previously and will only be briefly described here. ${ }^{2}$ The detector consists of a scientific grade slow scan CCD coupled to a YAG scintillator by a fiber optic reducer. During operation the CCD is cooled to $-40^{\circ} \mathrm{C}$ by a thermoelectric cooler. High quality patterns have been recorded with this detector with accelerating voltages of 5 to $40 \mathrm{kV}$ and beam currents as low as $10^{-10} \mathrm{~A}$. The images obtained with the detector are significantly improved by a procedure called flat-fielding. The raw patterns consist of the detailed crystallographic information superimposed on a slowly changing background intensity and a fine 'chicken wire' pattern due to defects in the fiber optic bundle. An image is then obtained which contains the background intensity and the 'chicken wire' pattern, but no crystallographic information. The raw image containing the crystallographic information is then normalized with the image that only contains the background intensity and the detail due to the fiber optic bundle. The resulting flat fielded image is immediately available for analysis.

Optical metallography of the creep tested ailoy showed the presence of two precipitate phases. Backscattered electron imaging of polished and etched specimens showed that one of the phases imaged much brighter than the other as shown in Figure 1. Identification of the second phase precipitates was attempted using TEM with little success due to difficulties in thinning the W-rich phase and to the small volume fraction of the Cr-rich phase. EDS analysis showed that the bright phase was mostly W and the darker imaging phase was mostly $\mathrm{Cr}$. BEKP's were obtained at $30 \mathrm{kV}$ from the metallographically polished and etched specimens that were tilted $70^{\circ}$ from the horizontal position. BEKP's were collected by holding the beam stationary, in a manner similar to the collection of $\mathrm{X}$-ray spectra, on the precipitates visible in the backscattered electron image. The specimen height was carefully reproduced by focusing with the mechanical height control to ensure that the location of the pattern on the detector did not change.

Figure $2 \mathrm{a}$ and $\mathrm{b}$ show BEKP's obtained from the W containing and the $\mathrm{Cr}$ containing precipitates. The differences between the patterns are immediately obvious. In order to index these patterns it is important that the center of the pattern and the camera length are accurately known. ${ }^{2}$ The interzonal angles measured from the experimental patterns are compared with those calculated for candidate compounds. Once agreement is found, simulated patterns are calculated and compared with the experimental patterns. The simulation utilizes structure factor information in order to determine if specific lines are allowed by the space group and the atom locations. It has been our observation that the relative intensities are in good agreement with the calculated intensities. Figure $3 \mathrm{a}$ and $\mathrm{b}$ show simulated patterns which show excellent agreement with the experimental patterns shown in Figure 2 and $b$, respectively. Thus, the bright $W$ containing precipitates can be identified as $\mathrm{M}_{6} \mathrm{C}$ ( Figures $2 \mathrm{a}$ and $3 \mathrm{a}$ ) and the darker $\mathrm{Cr}$ containing precipitates can be identified as $\mathrm{M}_{23} \mathrm{C}_{6}$ (Figures $2 \mathrm{~b}$ and $3 \mathrm{~b}$ ).

Through the combination of BEKP and EDS, precipitates that formed in a Ni-based superalloy were identified as $\mathrm{M}_{6} \mathrm{C}$ and $\mathrm{M}_{23} \mathrm{C}_{6}$. Phase identification utilizing $\mathrm{BEKP}$ has been used to identify crystallographic phases in many metals, semiconductors and ceramics. The ability of the CCD-based detector to collect high quality patterns enables on-line analysis of the patterns. The combination of

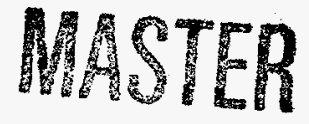


diffraction information from BEKP with EDS information holds the promise of a powerful new tool for materials characterization.

\section{References}

1. R. P. Goehner, et al. Proc. Ann. EMSA Meeting, 50 (1992) 1310.

2. J. R. Michael and R. P. Goehner, MSA Bulletin, 23 (1993) 168.

3. This work was supported by the U. S. Department of Energy under contract DE-AC04-76DP00789.

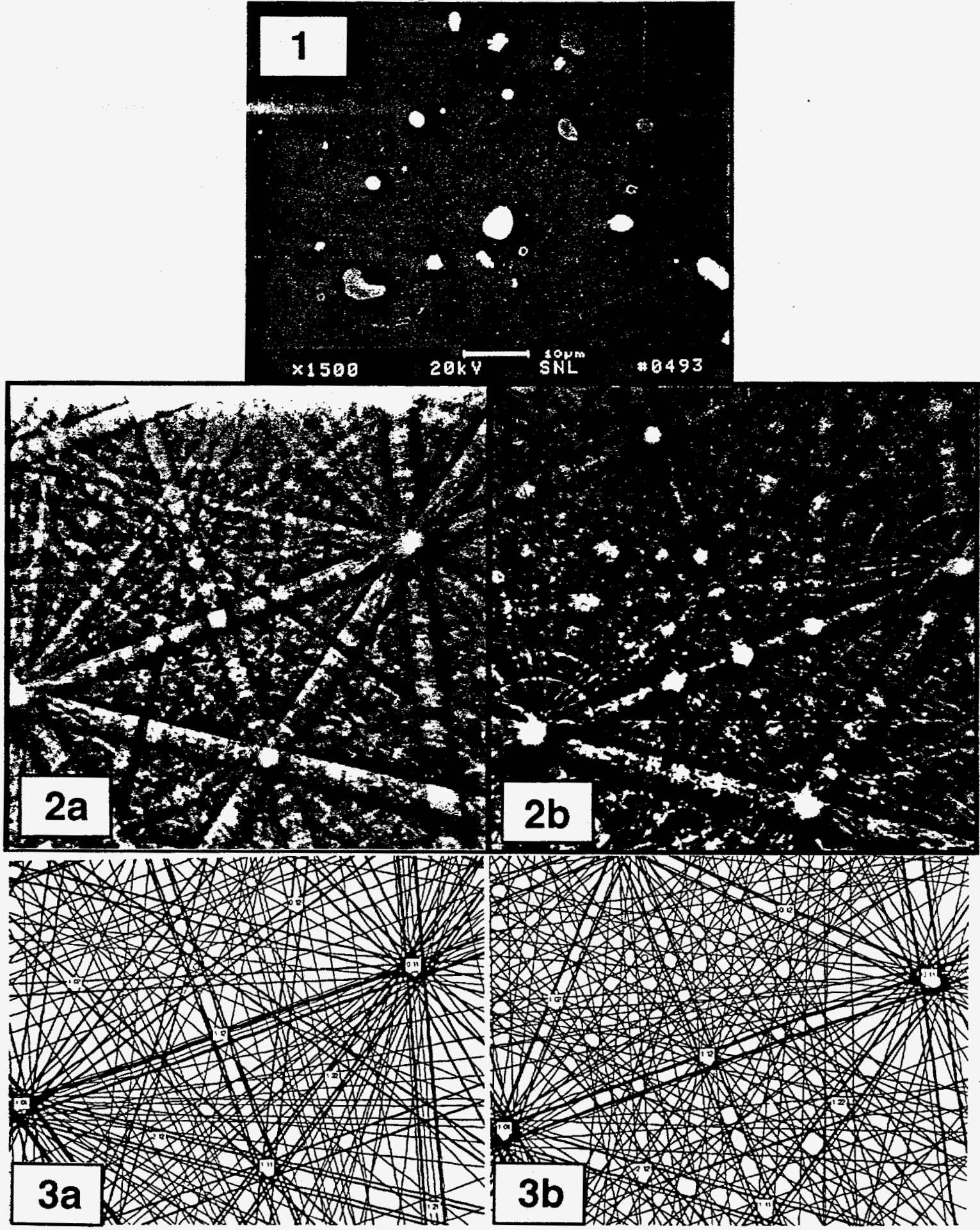

Fig. 1 BSE image that shows the light and dark precipitate phases.

Fig. 2 BEKP's of the phases in fig. 1 ( $a$. light phase, b. dark phase)

Fig. 3 Simulated patterns of the light and dark phases( a. $M_{6} C$, light phase and $b . M_{23} C_{6}$, dark phase). 


\section{DISCLAIMER}

This report was prepared as an account of work sponsored by an agency of the United States Government. Neither the United States Government nor any agency thereof, nor any of their employees, make any warranty, express or implied, or assumes any legal liability or responsibility for the accuracy, completeness, or usefulness of any information, apparatus, product, or process disclosed, or represents that its use would not infringe privately owned rights. Reference herein to any specific commercial product, process, or service by trade name, trademark, manufacturer, or otherwise does not necessarily constitute or imply its endorsement, recommendation, or favoring by the United States Government or any agency thereof. The views and opinions of authors expressed herein do not necessarily state or reflect those of the United States Government or any agency thereof. 


\section{DISCLAIMER}

Portions of this document may be illegible in electronic image products. Images are produced from the best available original document. 